\title{
A Framework for Web GIS Development: A Review
}

\author{
Ezekiel Kuria \\ KCA University \\ P.O.Box 56808-00200, Nairobi- \\ Kenya
}

\author{
Stephen Kimani \\ Jomo Keyatta University of \\ Agriculture and Technology \\ P.O.Box Box 62000 \\ Nairobi-Kenya
}

\author{
Agnes Mindila \\ Jomo Keyatta University of \\ Agriculture and Technology \\ P.O.Box Box 62000 \\ Nairobi-Kenya
}

\begin{abstract}
In this age of information where petabytes of data is generated every day, there is need to utilize this data to solve day-to-day problems encountered in the modern society. For this reason, Geospatial Information Systems (GIS) have become ubiquitous. The curation, data visualization on maps, geocoding of the same, and online deployment using web 2.0 technologies are user-generated content that are interactive and geo-located. Collectively, when GIS is delivered via internet technologies, it is termed web GIS. Over the years, Web GIS has evolved and gained prominence. This paper explores the structure of Web GIS, evaluates various methodologies currently employed by developers in the design, development and implementation of Web GIS systems and proposes a methodology for developing a standard Web GIS based on evaluation criteria.
\end{abstract}

\section{General Terms}

Web Development, Web Applications, GIS Applications.

\section{Keywords}

Geographic Information Systems, Web GIS, Web Development, Web mapping, Software Development Life Cycle.

\section{INTRODUCTION}

Geographic Information System (GIS) is a framework designed to capture, store, manipulate, analyze, manage, and present spatial or geographic data. The pivotal components on a GIS are Hardware, Software, data and users. A 3-tier perspective helped in the examination of GIS components [16].It gave a detailed technological understanding of a GIS, comprising of; a geographic data collection component, database component, and presentation component. Web GIS is a type of distributed information system, comprising of at least a server and a client, where the server is a GIS server and the client is a web browser, desktop application, or mobile application. Simply put, a Web GIS is a GIS system that uses web technologies for dissemination of information and functionalities, as well as communication among different components of a system.

Web GIS should not be confused with Internet GIS; in as much as they may be used interchangeably in some instances, there is a slight difference between the two. The internet supports many services and Web is one of the services the internet supports. A system can be termed as internet GIS if it uses more internet services as opposed to being singularly web based. Web GIS is also in some instances replaceable with geospatial Web or the GeoWeb.

\section{PREVIEW OF THE LITERATURE}

This paper presents a review of the methodologies by various researchers and developers in the development of Web GIS, and gives future recommendations.

\subsection{Web GIS Architecture}

The evolution of Web GIS has been steady, progressing in tandem with the growth of the internet and the advancement of hardware and software. The web provides the end user with the ability to interact with the data and make better decisions from it. The basic architecture of a web GIS application is the client-server architecture; this is because the standard of geodata is very specific in the sense that it requires a map server on top of the web server and a database compliant with geodata, while most other websites do not require these extra technologies to function properly [12].

In their study, [12] stated that the web browser is the interface through which the user accesses the web GIS application. Middleware facilitates the sending of requests and responses between the client and server. The web server receives user requests and in turn sends back the requested files (HTML, binary images) which includes the web pages the user views, using the Hypertext Transfer Protocol (HTTP). A map server allows for the sharing, processing and editing of geospatial data, which is then stored in a geodatabase (GIS database). GIS software are programs that have the capabilities required for the processing of geospatial data through the process of spatial analysis. They [12] sated that the system architecture is a blueprint for how the application should work once completed and forms the basis upon which the design process done. These formulate the key elements for the success of a web GIS system-which are implemented in the application through the five basic components expected of every web GIS application; they include a web application, digital base-maps, operational layers, tasks and tools, and one or more geodatabases. The web application take a client-server status and provides the client with the software interface through which they visualize, interact, and manipulate the geo-data. A digital base map is essential in web GIS applications as it provides the geographic context for each application. The criteria for selection of a base map depends on the type of application at hand (for example, hydrology, parcels, electrical utilities, and conservation). For example, in a web GIS application aimed at water flow conservation, highresolution orthoimagery would be an appropriate base map for digitizing wetlands. Base maps typically tend to be static and updated on an infrequent basis.

More elaborations indicated that operational layers are small set of layers that work directly with, or are the result of an operation (such as a query) in a web GIS application [12], and these layers consist of, but are not restricted to the following:

1) Observations or sensor feeds; any information that reflects status or situational awareness, say, crime locations, traffic sensor feeds, real-time weather readings et cetera.

2) Operational layers; used as inputs into analytic operations that are computed on the server. They 
consist editing and data access layers, which are the map layers that users work with to edit features, perform queries, and select features for input to analysis.

3) Query results; applications make a query request to the server and return a set of records as results to said query. These include a set of individual features or attribute records. Users can display and work with these results as map graphics in their web GIS applications.

4) Result layers; are derived from analytic models.

Most GIS applications and users work with operational information (sometimes multiple operational layers) on top of their base map [12], this provides the geographic context, other times, the operational layer displayed underneath other layers that help provide locational context. For example, when you classify and display ZIP or postal code areas by demographic information, you often overlay these results with transportation lines and place-names to provide locational context. Operational layers are often dynamic. They mostly work within a focused range of map scales and resolutions. Some Web GIS applications provide tools that perform processes beyond mapping.

Every application is as good as its geospatial data management framework. It is comprised of a geodatabase (one or more), a collection of shape files, various tabular databases and spreadsheets, CAD files, design files, imagery and HTML web pages.

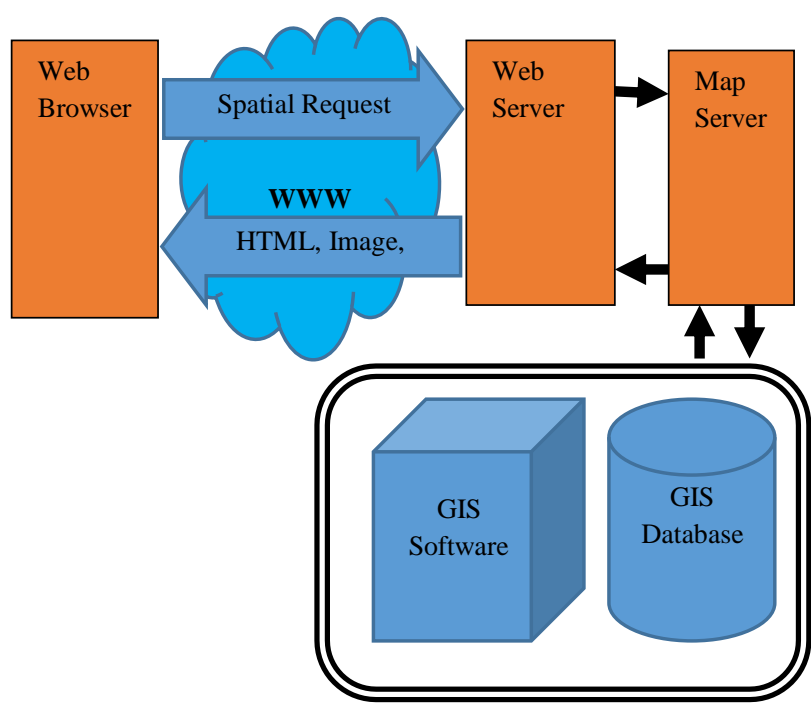

Figure 1: Standard Web GIS Architecture [12]

\subsection{Software Development Methodologies}

Several software development models and methodologies exist for the development of web applications, case in point, web GIS applications. Models and methodologies describe the whole cycle of development stages including, achievement of functionality, release and maintenance. Some of these models are; the Waterfall Model, V-Shaped Model, Prototyping Model, Spiral Method (SDM), Iterative \& Incremental Method, RAD (Rapid Application Development) model and Agile development.
According to [15], the Waterfall model is the most commonly used methodology, it is a linearly sequential model where the completion of each step is imperative to commencement of the next, and the requirements for your application have to be very clear before commencing the development. In summary, the steps involved in Waterfall methodology includes planning, analysis, design, implementation, testing and maintenance. This method is very clear on requirements before development commences. In Waterfall, each phase completes before the next, and it requires minimal resources, and thorough documentation [12]. They also found out that this methodology is faulty because problems from one phase is transferable to the next.

The V-Shaped model (validation and verification) is an extension of the Waterfall model. In the V-Shaped model, steps bent upwards after the implementation and coding phase, to form the typical V shape. The major advantage of this model over the Waterfall model is that it verifies each step before progressing, reducing the transfer of error. The testing happens in tandem with development. A big challenge in this model is that, it is rigid and less flexible to change, and it disregards risk analysis activities [14].

Prototyping is all activities that entails the initial stages of creating a software application; it is an incomplete version of software/application. It visualizes the main features and components of the software and provide a deeper understanding of the application to be developed. Prototyping significantly reduces the number of unforeseen problems in the future of the application development process. This category has two models; throwaway prototyping and evolutionary prototyping. While evolutionary prototyping gradually evolves into the final system through iterative incorporation of user feedback, the throwaway prototype does not evolve; or rather integrate into the final product [9].

Spiral Development Model (SDM) merges elements of design and prototyping-in-stages. Development following this SDLC begins with a few requirements; it then goes through each development phase for those requirements. This will comprise the first iteration. Based on this initial iteration, subsequent iterations add more functionality and seal loopholes. This increment in functionality takes place in "spirals" until the end of the development process [10]. According to [10] the SDM combines features of prototyping and Waterfall models. It is most favorable for large, expensive, and complicated projects as it mitigates risk and involves developers throughout the process. It is however very costly and time consuming and requires special skills to evaluate risks and assumptions.

The iterative model filled loopholes in Waterfall model. The system allows for repeated cycles (iterative), in smaller portions each time (incremental), this allows software developers to take advantage of knowledge from development of the earlier versions of the applications. More often than not SDM consists of several mini Waterfalls or mini V-Shaped model [10].

Agile is an English word with a meaning, "to move quickly or progress rapidly." Naturally, Agile development is a model based on the iterative and incremental development model, where a skilled adaptive team responds to frequently changing requirements. This model ascertains rapid progress from start to finish. Its main advantage is its ability to respond to the changing requirements and the reduced time to delivery. This model is however very inefficient and difficult to employ for large projects [11]. 
In their study, The RAD (Rapid Application Development) model based on prototyping and iterative development with no specific planning involved. It employs minimal planning instead of rapid prototyping as in Agile development. RAD gathers customer requirements via workshops or focus groups, early testing of the prototypes by the customer using iterative concept, reuse of the existing prototypes (components), continuous integration and rapid delivery [2].

\subsection{Previous Development Methodologies}

Web-GIS systems exhibit the characteristics of both GIS and the web. Developers are thus at liberty to employ any of these models in their development process based on the criteria aforementioned [16].

A design process of Web-GIS was tested by [1] for Iran during the development of a rudimentary road information system. Their development cycle took eight major activities starting with the requirement analysis and ending with ongoing use and maintenance of the Web GIS system. They followed the procedural Waterfall SDLC model. The steps involved in the Waterfall model employed for the Iranian road information system included, determination of system requirements, conceptual design, hardware and software survey, database design and construction, acquisition of GIS hardware and software, web GIS system integration, application development, and finally, web GIS use and maintenance. According to [1] the Waterfall model wins when it comes to its simplicity, however it has the shortcomings of not being practical for large projects as it takes too long and places no emphasis on critical matters such as, testing and user involvement during the development process. RAD-based methodology for GIS development focused on the interoperability of the application with web database applications, and varied innovations such as, a georeferenced abstraction, using SQL column data types to specify the user interface without warranting the need for a script [2]. It followed the principles of code minimization, and shares authentication of existing web applications, and the ease of use of graphic editing functionalities. Nonetheless, the approach is a very broad approach to web-GIS development. In addition, the order of precedence in which to apply the framework is not clearly defined [2].

A web GIS Application for visualization and analysis of health in a community for out of hospital cardiac arrest patterns in the United States [3]. The Agile development methodology was used as a development process; the five stages of application development set forth in the model were identification and assessment of client and users' needs, goal/task analysis, initial prototype design, evaluations and refining of prototypes and final stage application, and project implementation and maintenance. Iterations solved the usability problems associated with interactive web mapping such us; poor design of user interface, misinterpretation of published maps, and poor visualization of search results. All feedback integrated into the design of the application in the next iteration. The project sought to achieve both 'usability' and 'usefulness' in web map design [3].

A cost effective mobile mapping solution for collection of spatial data using open - source technologies dubbed m-Sport GIS was developed [4]. This web-GIS application is currently in use by the Mozambican government to manage all of its sports resources. The resulting solution utilized web and mobile technologies. Some of the technologies and APIs used include Sencha Touch and Apache Cordova. The application was designed to run on Android mobile phones; employing the use of its camera, GPS and file system. As several Mozambican areas faced constant network limitations at the time, the development also considered the offline usability of the resulting application; this warranted the use of a tile caching method in addition to the Web Map Service (WMS). To achieve this, researchers employed an adaptation of the prototyping and Agile SDLC methodology. According to [6] the methodology does not capture all trivial requirements; hence, contingencies are unavoidable. This methodology is also faster, however it is very tedious for the developers [6].

A research on Web-GIS applicability was conducted [5]. They carried out a research on the applicability of a web-GIS enabled soil information system in agricultural land use planning in the United Arab Emirates. The development of this system followed a classic procedural SDLC. This methodology is systematic; from this, we can infer that a Waterfall model can develop the system. Their study explained that this methodology increased the probability of completing the project within the prescribed time, whilst maintaining the quality of the system by the technological standards of the time.

\section{METHODOLOGY}

This study adopted the most appropriate method for prioritizing elements of Web-GIS usability as depicted by [8]. The creative process from [8] demands that problem analysis task comes first, and it involves reviewing existing literature looking for information that could enhance understanding of the methods that can prioritize elements of the usability of Web-GIS. Relevancy of the topic formed an important criteria used for analyzing all the articles and peer reviewed papers. Five key papers were of core interest in this paper, and evaluated as depicted in Table1.

\section{FINDINGS}

This section summarizes evaluation for different methodologies used in the web-GIS projects aforementioned.

Table 1: Evaluation Methodologies

\begin{tabular}{|c|c|c|c|c|}
\hline $\begin{array}{c}\text { Project } \\
\text { [Reference } \\
]\end{array}$ & $\begin{array}{c}\text { Yea } \\
\mathbf{r}\end{array}$ & Scope & $\begin{array}{c}\text { Complexit } \\
\mathbf{y}\end{array}$ & $\begin{array}{c}\text { Methodolog } \\
\mathbf{y}\end{array}$ \\
\hline$[1]$ & 2002 & Small & $\begin{array}{c}\text { Not } \\
\text { complex }\end{array}$ & Waterfall \\
\hline$[2]$ & 2010 & $\begin{array}{c}\text { Mediu } \\
\mathrm{m}\end{array}$ & $\begin{array}{c}\text { Moderately } \\
\text { complex }\end{array}$ & RAD \\
\hline$[3]$ & 2013 & $\begin{array}{c}\text { Mediu } \\
\mathrm{m}\end{array}$ & Complex & Agile \\
\hline$[4]$ & 2014 & $\begin{array}{c}\text { Wide } \\
\text { Complex }\end{array}$ & $\begin{array}{c}\text { Prototyping } \\
\text { and Agile }\end{array}$ \\
\hline$[5]$ & 2014 & Small & $\begin{array}{c}\text { Not } \\
\text { complex }\end{array}$ & Waterfall \\
\hline
\end{tabular}

Table1 depicts who did the project, the year of project, scope in terms of de-limits, complexity-in terms of the technology used, and the methodology employed. A comparison between the aforementioned methodologies and the criteria indicated by virtue of mean that the Waterfall methodology ranks high followed by RAD and Agile in equal measure as depicted in Figure2. 
Table 2: Comparing Waterfall, RAD, and Agile

\begin{tabular}{|c|c|c|c|}
\hline & \multicolumn{3}{|c|}{ Methodology } \\
\hline Criteria & Waterfall & RAD & Agile \\
\hline Rules & $\checkmark$ & $\checkmark$ & $\checkmark$ \\
\hline Coverage & $\checkmark$ & $\checkmark$ & $\checkmark$ \\
\hline Design & & $\checkmark$ & $\checkmark$ \\
\hline $\begin{array}{c}\text { Inter-stage } \\
\text { communication }\end{array}$ & & & $\checkmark$ \\
\hline Teachable & $\checkmark$ & & \\
\hline $\begin{array}{c}\text { Design for } \\
\text { change }\end{array}$ & & $\checkmark$ & $\checkmark$ \\
\hline $\begin{array}{c}\text { Simplicity and } \\
\text { pragmatism }\end{array}$ & $\checkmark$ & & \\
\hline Participation & $\checkmark$ & $\checkmark$ & $\checkmark$ \\
\hline
\end{tabular}

Table 3: Descriptive Table Generated from Table2

\begin{tabular}{|c|c|c|c|c|c|}
\hline & $\mathrm{N}$ & Minimum & Maximum & Mean & $\begin{array}{c}\text { Std } \\
\text { Deviation }\end{array}$ \\
\hline Waterfall & 5 & 1.00 & 8.00 & 4.6000 & 3.04959 \\
\hline RAD & 5 & 1.00 & 8.00 & 4.0000 & 2.91548 \\
\hline Agile & 6 & 1.00 & 8.00 & 4.0000 & 2.60768 \\
\hline $\begin{array}{c}\text { Valid } \\
\text { N(Listwise) }\end{array}$ & 5 & & & & \\
\hline
\end{tabular}

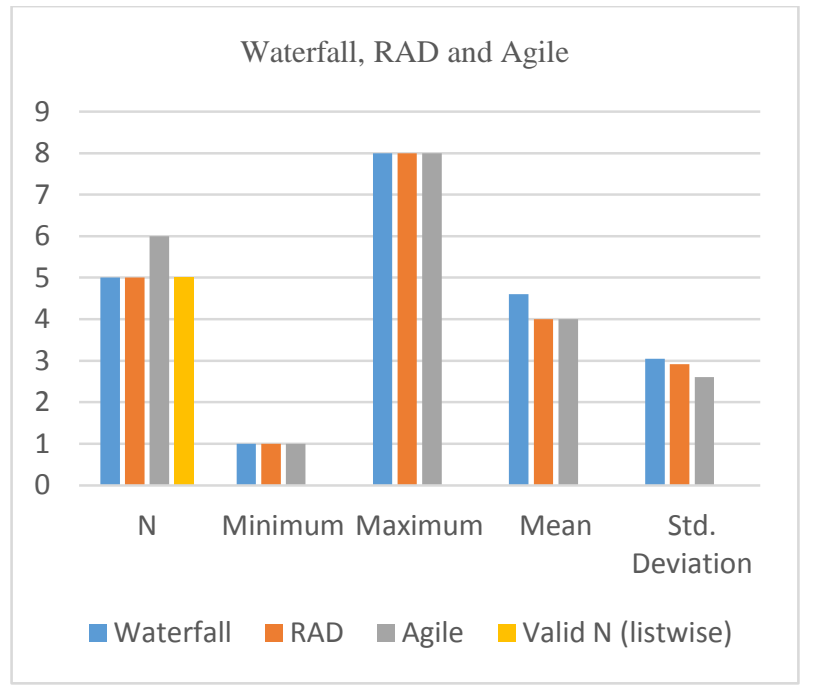

Figure 2: Graphical Representation of Waterfall, RAD, and Agile Evaluation

\section{DISCUSSION}

Table1 indicates that the methodologies previously used for web-GIS development projects does not reveal any bias towards a particular methodology with regards to the time/year it was developed. Two groups of researchers; [1] and [5], they both used the Waterfall methodology despite being-carried out 13 years part; each project selected a suitable methodology based on its scope, technical and temporal requirements. The common denominator between complex and wide projects such as that by [4] and [3] was the Agile methodology.

Each methodology has its own strengths and weaknesses thus the selection of any of one for a particular development exercise is done based on the purpose of the project; its scope, time constraint, budget and availability of skilled labor, as elaborated by [16]. It comprised of the following:

1) Rules: Selected methodology should provide clear formal guideline to cover all the tasks and deliverables of the projects.

2) Coverage: Methodology should cover the entire development processes.

3) Design: Methodology should separate the physical and logical design.

4) Inter-stage communication: Work in each stage passed to the next subsequent stage.

5) Teachable: Knowledge of technique easily shared.

6) Designing for change: Design should allow for modification at a later stage.

7) Simplicity and pragmatism: Methodology should be easy to use.

8) Participation: Encourages involvement of users and stakeholders.

\section{CONCLUSION}

With advancements in software and hardware, as well as the growth of the internet, GIS has begun to adapt to the same as well. Devices have become smaller, lighter and powerful, and can be used on the go. As such, all GIS development activities should take place in a manner that lives up to the growth of technology and the ever growing needs and demands of GIS users. GIS applications need to be deployable, scalable and accessible, particularly Web-GIS which should be able integrate remote content with that available locally. This is best achieved by employing Agile development in the development of web GIS. Even though Waterfall ranks high in-terms of adoption, Agile methodology stands proposed to be the most efficient development methodology for web GIS applications. This is because Agile development ensures easy collaboration, comprehensive design and testing, flexibility to change as the solution evolves and timely delivery. The Agile also has its fair share of shortcomings. Particularly for large projects: it is intensive and highly demanding on developer and is unpredictable to some extent, and as of the quantification of effort taken to complete the project, this could not measure accurately at the start of the project.

\section{REFERENCES}

[1] A. A. Alesheikh, H. Helali and H. A. Behroz, "Web GIS: Technologies and its Applications," in Symposium on Geospatial Theory, Processing and Applications, Ottawa, 2002.

[2] R. Cavaco, R. Sequeira, M. Araújo and M. Calejo, "Rapid GIS Development: a model-based approach focused on interoperability," in 13th AGILE International Conference on Geographic Information Science, Guimarães, Portugal, 2010.

[3] H. Semple, H. Quin and C. Sasson, "Development of a Web GIS Application for Visualizing and Analyzing Community Out of Hospital Cardiac Arrest Patterns," Online Journal of Public Health Informatics, 2013. 
[4] C. E. d. A. Freire and M. Painho, "Development of a Mobile Mapping Solution for Spatial Data Collection using Open-Source Technologies," Elsevier, pp. 481-40, 2014.

[5] M. A. Abdelfattah and A. T. Kumar, "Aweb-based GIS enabled soil information system for the United Arab Emirates and its applicability in agricultural land use planning," Saudi Society for Geosciences, p. 1813, 2014.

[6] R. Vidgen, "Constructing a Web Information System Development Methodology," Blackwell Science Ltd, p. 247-261, 2002.

[7] D. Vavpotič, M. Bajec and M. Krisper, "Measuring and Improving Software Development Methodology Value By Considering Technical and Social Suitability of its Constituent Elements," in Advances in Theory, Practice and Education-Proceedings of the 13th International Conference on IS Development, Vilnius, Lithuania, 2004.

[8] S. N. Mwendia, P. Waiganjo and P. Waiganjo, "Dynamic Heuristics: Greedy Search: A Mobile Information Retrieval Algorithm for Ambient Learning Systems," in AfriCHI'16 Proceedings of the First African Conference on Human Computer Interaction, Naironi, Kenya, 2016.

[9] A. Mishra and D. Dubey2, "A Comparative Study of Different Software Development Life Cycle Models in Different Scenarios," International Journal of Advance Research in Computer Science and Management Studies(IJARCSMS), pp. 64-69, 2013.

[10] V. Massey and K. J. Satao, "Comparing Various SDLC Models and the New Proposed Model on the Basis of
Available Methodology," International Journal of Advanced Research in Computer Science and Software Engineering, pp. 170-177, 2012

[11] M. S. Krishnan, "Software Development Risk Aspects and Success Frequency on Spiral and Agile Model," International Journal of Innovative Research in Computer and Communication Engineering(IJIRCCE) pp. 301-310, 2015.

[12] I. Heru, D. Abner and S. Andri, "Webgis-based Irrigation basic Map Model of Merauke Regency Papua," International Journal of Computer Applications(IJCA), pp. 21-24, 2016.

[13] M. J. Escalona, A. Torres-Zenteno, J. Gutierrez, E. Martins, R. d. S. Torres and M. C. C. Baranauskas, "A Development Process for Web Geographic Information System-A Case Study," Requirements Engineering, 2008.

[14] Y. Berra, "Amazon," 8 October 2019.[Online].Available: https://s3.apsouth1.amazonaws.com/btechktu/placement/ se.pdf.

[15] S. Balaji and M. S. Murugaiyan, "Waterfall Vs V-Model Vs Agile: A Comparative Study on SDLC," International Journal of Information Technology and Business Management(JITBM), pp. 26-30, 2012.

[16] F. Ananda, D. Kuria and M. Ngigi, "Towards a New Methodology for Web GIS Development," International Journal of Software Engineering \& Applications (IJSEA), pp. 47-66, 2016. 